\title{
OPTIMAL CONTROL IN THE MATHEMATICAL MODEL OF INTERNAL WAVES
}

\author{
K. Yu. Kotlovanov ${ }^{1}$, kotlovanovki@susu.ru, \\ E. V.Bychkov ${ }^{1}$, bychkovev@susu.ru, \\ A. V. Bogomolov', a.v.bogomolov@gmail.com \\ 1 South Ural State University, Chelyabinsk, Russian Federation \\ 2 St. Petersburg Institute for Informatics and Automation of RAS, Saint-Petersburg, \\ Russian Federation
}

The paper presents the results of the study of the problem on the optimal control to solutions for a mathematical model of internal waves, which is based on a linear system of equations of hydrodynamics. This model describes the propagation of waves in a homogeneous incompressible stratified fluid. The mathematical model includes the Sobolev equation, the Cauchy and Dirichlet condition. We use a parallelepiped as a considered domain in the mathematical model. The paper shows existence and uniqueness of a strong solution to the Cauchy - Dirichlet problem for the Sobolev equation. Also, we obtain the sufficient conditions for existence and uniqueness of a solution to the problem on optimal control to such solutions in Hilbert spaces. Proof of existence and uniqueness of a strong solution is based on the theorem for an abstract incomplete inhomogeneous Sobolev type equation of the second order and the theory of relatively $p$-bounded operators. In this paper, we present the theorem on existence and uniqueness of the optimal control for the problem under study, which is based on the works of J.-L. Lyons.

Keywords: Sobolev type equations; relatively p-bounded operator; strong solution; optimal control.

\section{Introduction}

Dynamics of particle oscillations of a homogeneous incompressible fluid, which rotates with the constant angular velocity $\Omega$, is described by the linear system of hydrodynamic equations (the system of Sobolev equations [1])

$$
\left\{\begin{array}{l}
\nu_{t}+\frac{1}{\rho_{0}} \nabla p+2[\Omega \times \nu]=f(x, t), \\
\rho_{t}=0 \\
\nabla \nu=0
\end{array}\right.
$$

where $\nu=\{u, v, w\}$, while $\rho_{0}=$ const is the equilibrium density and the buoyancy frequency is equal to zero. If we direct the axis $O z$ collinearly to the vector $\Omega$, then we obtain the equation for the vertical component of the velocity of fluid particles (the Sobolev equation [1])

$$
\Delta w_{t t}+F^{2} w_{z z}=f(x, t),
$$

where $2[\Omega \times \nu]=\{-F v, F u, 0\}$, and $F=2 \Omega$ is the Coriolis parameter. Wave solutions that satisfy equation (2) are called inertial or gyroscopic waves propagating on the surface of the rotating fluid. In the paper [1], a solution to equation (2) is obtained in an unbounded domain by the Green's function method. The paper [2] describes the behavior of solutions to two-dimensional Hamiltonian systems arising in the theory of small oscillations of a 
rotating ideal fluid, and constructs a mathematical model of the generation of a vortex structure.

Let $D$ be a bounded domain that belongs to $\mathbb{R}^{3}$ and has a smooth boundary $\partial D$. For the function $w=w(x, t)$, we impose the Dirichlet condition

$$
w(x, t)=0, \quad(x, t) \in D \times \mathbb{R}
$$

at the boundary of the domain $D$, and the Cauchy condition

$$
w(x, 0)=0, \quad w_{t}(x, 0)=0
$$

In this paper, we study the optimal control problem on finding the pair $(\hat{w}, \hat{u})$, where $\hat{w}$ is the solution to problem (2), (4), and $\hat{u} \in \mathfrak{U}_{a d}$ is the control that satisfies the relation

$$
J(\hat{w}, \hat{u})=\min _{(w, u) \in \mathfrak{X} \times \mathfrak{U}_{a d}} J(w) .
$$

Here $J(w, u)$ is the quality functional constructed in a special way, and $\mathfrak{U}_{a d}$ is the set, which is closed and convex in the control space $\mathfrak{U}$.

Let us find a solution to problem (2)-(5) in the framework of the theory of Sobolev type equations. First, consider the Cauchy problem for the incomplete inhomogeneous Sobolev type equation of the second order

$$
\begin{gathered}
A \ddot{w}=B w+y, \\
\dot{w}(0)=w_{1}, w(0)=w_{1},
\end{gathered}
$$

where the operators $A, B \in \mathcal{L}(\mathfrak{X} ; \mathfrak{Y})$, the function $y:[0, \tau) \subset \mathbf{R}_{+} \rightarrow \mathfrak{Y}(\tau<\infty)$, and $\mathfrak{X}, \mathfrak{Y}$ are Hilbert spaces.

The paper is based on the theory of relatively bounded operators, degenerate semigroups of operators [3] and the theory of incomplete Sobolev type equations of the high order [4]. The monographs [3, 5] study in detail Sobolev type equations and equations that are not resolved with respect to the highest time derivative. In the monograph [5], various classes of Sobolev type equations are introduced and equation (2) is referred to simple Sobolev type equations. Sobolev type equations represent a significant field of non-classical equations of mathematical physics. Optimal control problems for models of mathematical physics represent a promising direction. New statements of optimal control problems arise. For example, we note optimal control of solutions to stochastic equations [6], [7], optimal control of solutions to a multipoint initial-final value problem [8]. Optimal control problems are considered in $[9,10]$ for first-order Sobolev type equations and in [11] for high-order equations.

\section{Relatively $p$-bounded Operators}

Definition 1. The set $\rho^{A}(B)=\left\{\mu \in \mathbb{C}:(\mu A-B)^{-1} \in \mathcal{L}(\mathfrak{Y} ; \mathfrak{X})\right\}$ is said to be the resolvent set of the operator $B$ with respect to the operator $A$ (in short, $A$-resolvent set of the operator $B$ ). The set $\mathbb{C} \backslash \rho^{A}(B)=\sigma^{A}(B)$ is called the spectrum of the operator $B$ with respect to the operator $A$ (in short, $A$-spectrum of the operator $B$ ). 
Definition 2. The operator-functions

$$
(\mu A-B)^{-1}, \quad R_{\mu}^{A}=(\mu A-B)^{-1} A, \quad L_{\mu}^{A}=A(\mu A-B)^{-1}
$$

with the domain $\rho^{A}(B)$ are called the resolvent, right resolvent, left resolvent of the operator $B$ with respect to the operator $A$ (in short, $A$-resolvent, right $A$-resolvent, left $A$-resolvent of the operator $B$ ), respectively.

Definition 3. The operator $B$ is called spectrally bounded with respect to the operator $A$ (in short, $(A, \sigma)$-bounded), if

$$
\exists a>0 \forall \mu \in \mathbb{C}:(|\mu|>a) \Rightarrow\left(\mu \in \rho^{A}(B)\right) .
$$

Lemma 1. [3] Let the operator $B$ be $(A, \sigma)$-bounded. Then the operators

$$
P=\frac{1}{2 \pi i} \int_{\Gamma} R_{\lambda}^{A}(B) d \lambda u Q=\frac{1}{2 \pi i} \int_{\Gamma} L_{\lambda}^{A}(B) d \lambda
$$

are projectors with $P: \mathfrak{X} \rightarrow \mathfrak{X}$ and $Q: \mathfrak{Y} \rightarrow \mathfrak{Y}$. Here $\Gamma=\{\lambda \in \mathbb{C}:|\lambda|=r>a\}$.

Let $\mathfrak{X}^{0}=\operatorname{ker} P, \mathfrak{Y}^{0}=\operatorname{ker} Q, \mathfrak{X}^{1}=\operatorname{im} P, \mathfrak{Y}^{1}=\operatorname{im} Q$. Denote by $A_{k}\left(B_{k}\right)$ the restriction of the operator $A(B)$ to the subspace $\mathfrak{X}^{k}, k=0,1$.

Theorem 1. [3] Let the operator $B$ be $(A, \sigma)$-bounded. Then

(i) the operators $A_{k}, B_{k}: \mathfrak{X}^{k} \rightarrow \mathfrak{Y}^{k}, k=0,1$;

(ii) there exists the operator $B_{0}^{-1} \in \mathcal{L}\left(\mathfrak{Y}^{0}, \mathfrak{X}^{0}\right)$;

(iii) there exists the operator $A_{1}^{-1} \in \mathcal{L}\left(\mathfrak{Y}^{1}, \mathfrak{X}^{1}\right)$;

(iv) the operator $B_{1} \in \mathcal{L}\left(\mathfrak{X}^{1}, \mathfrak{Y}^{1}\right)$.

Under the conditions of Theorem 1 , we construct the operators $H=B_{0}^{-1} A_{0} \in \mathcal{L}\left(\mathfrak{X}^{0}\right)$ and $S=A_{1}^{-1} B_{1} \in \mathcal{L}\left(\mathfrak{X}^{1}\right)$. Then

$$
(\mu A-B)^{-1}=\left(-\sum_{k=0}^{\infty} \mu^{k} H^{k}\right) B_{0}^{-1}(\mathbb{I}-Q)+\sum_{k=1}^{\infty} \mu^{-k} S^{k-1} A_{1}^{-1} Q .
$$

Definition 4. An infinitely distant point of the $A$-resolvent of the operator $B$ is called

(i) a removable singular point, if $H \equiv \mathbb{O}$;

(ii) a pole of the order $p$, if $H^{p} \neq \mathbb{O}, H^{p+1} \equiv \mathbb{O} ; p \in \mathbb{N}$,

(iii) an essentially singular point, if $H^{q} \neq \mathbb{O}, \forall q \in \mathbb{N}$.

Definition 5. The $(A, \sigma)$-bounded operator $B$ is called $(A, p)$-bounded, if the point $\infty$ is a pole of the order $p \in\{0\} \cup \mathbb{N}$ of its $A$-resolvent.

\section{Abstract Problem}

Let $\mathfrak{X}, \mathfrak{Y}$ be Hilbert spaces, $\mathcal{L}(\mathfrak{X})$ be the space of linear operators acting on the space $\mathfrak{X}$, the operators $A, B \in \mathcal{L}(\mathfrak{X} ; \mathfrak{Y})$. Consider the inhomogeneous linear Sobolev type equation

$$
A \ddot{w}=B w+y .
$$


Definition 6. The operator-function $V^{\bullet} \in C^{\infty}(\mathbb{R} ; \mathcal{L}(\mathfrak{X}))$ is called the propagator of inhomogeneous equation (9), if the vector function $w(t)=V^{t} v$ is a solution to (9) $\forall v \in \mathfrak{X}$.

Theorem 2. [4] Let the operator $B$ be $(A, \sigma)$-bounded. Then the formula

$$
V_{m}^{t}=\frac{1}{2 \pi i} \int_{\Gamma} \mu^{1-m}\left(\mu^{2} A-B\right)^{-1} A e^{\mu t} d \mu, m=0,1,
$$

where the contour $\Gamma=\{\mu \in \mathbb{C}:|\mu|=R>a\}$, defines the propagators of equation (6) for all $t \in \mathbb{R}$.

Lemma 2. (i) $V_{m}^{\bullet} \in C^{\infty}\left(\mathbb{R} ; \mathcal{L}\left(\mathfrak{X} ; \mathfrak{X}^{1}\right)\right),\left(V_{m}^{t}\right)_{t}^{(l)}=V_{m-l}^{t}$, where $m=0,1, l=0,1$;

$$
\text { (ii) }\left.\left(V_{m}^{t}\right)_{t}^{(l)}\right|_{t=0}=\mathbb{O} \text { for } m \neq l,\left.\left(V_{m}^{t}\right)_{t}^{(m)}\right|_{t=0}=V_{0}^{0}=P \text {. }
$$

Definition 7. The subspace $\mathcal{P} \subset \mathfrak{X}$ is called the phase space of homogeneous equation (6) if

(i) any solution $w=w(t)$ to equation (6) belongs to $\mathcal{P}$, i.e. $w(t) \in \mathcal{P}, \forall t \in \mathbb{R}$;

(ii) there exists the unique solution to problem (6), (7) for any $w_{0}, w_{1} \in \mathcal{P}$.

Theorem 3. [4] Let the operator $B$ be $(A, p)$-bounded. Let the vector function $y:(-\tau, \tau) \rightarrow \mathfrak{Y}$ be such that $y^{0} \in C^{2}\left((-\tau, \tau) ; \mathfrak{Y}^{0}\right)$, and $y^{1} \in C\left((-\tau, \tau) ; \mathfrak{Y}^{1}\right)$. Suppose that the initial values satisfy the relations

$$
\left(I-V_{0}^{0}\right) w_{m}=-\sum_{q=0}^{p} H^{q} B_{0}^{-1} \frac{d^{2 q+m}}{d t^{2 q+m}} y^{0}(0), \quad m=0,1 .
$$

Then there exists a unique solution to problem (6),(7), which can be represented in the form

$$
w(t)=-\sum_{q=0}^{p} H^{q} B_{0}^{-1}(\mathbb{I}-Q) y^{(2 q)}(t)+\sum_{m=0}^{1} V_{m}^{t} w_{m}^{1}+\int_{0}^{t} V_{1}^{t-s} A_{1}^{-1} Q y(s) d s, t \in(-\tau, \tau) .
$$

Definition 8. The vector function $w \in H^{2}(\mathfrak{X})=\left\{w \in L_{2}(0, \tau ; \mathfrak{X}): \ddot{w} \in L_{2}(0, \tau ; \mathfrak{X})\right\}$ is said to be a strong solution to equation (6), if $w$ converts (6) into identity almost everywhere on $(0, \tau)$. A strong solution $w=w(t)$ to equation (6) is called a strong solution to problem (6), (7) if $w$ satisfies (7).

The concept of a "strong solution" used in Definition 6 is introduced to distinguish the solution to equation (6) in this sense and the solution to (6), which is usually called "classical" one. The embedding $H^{2}(\mathfrak{X}) \hookrightarrow C^{1}([0, \tau] ; \mathfrak{X})$ is continuous, therefore Definition 8 is correct. Note that the classical solution to $(6),(7)$ is also a strong solution to the problem.

Let us construct the space $H^{2}(\mathfrak{Y})=\left\{v \in L_{2}(0, \tau ; \mathfrak{Y}): \ddot{v} \in L_{2}(0, \tau ; \mathfrak{Y})\right.$. The space $H^{2}(\mathfrak{Y})$ is a Hilbert space with the scalar product

$$
[v, w]=\sum_{q=0}^{2} \int_{0}^{\tau}\left\langle v^{(q)}, w^{(q)}\right\rangle_{\mathfrak{Y}} d t
$$


Theorem 4. [11] Let the operator $B$ be $(A, p)$-bounded. Then there exists a unique strong solution to problem (7) for equation (6) for any $w_{0}, w_{1} \in \mathfrak{X}$ and $y \in H^{2}(\mathfrak{Y})$.

Let us consider the optimal control problem for the solutions to problem (6), (7) with the penalty functional of the form

$$
J(w, u)=\sum_{q=0}^{2} \int_{0}^{\tau}\left\|w^{(q)}-\tilde{w}^{(q)}\right\|^{2} d t+\sum_{q=0}^{2} \int_{0}^{\tau}\left\langle N_{q} u^{(q)}, u^{(q)}\right\rangle_{\mathfrak{U}} d t
$$

where $N_{q} \in \mathcal{L}(\mathfrak{U}), q=0,1,2$, are positive definite and self-adjoint operators, $w$ is a solution to problem $(6),(7), \tilde{w}(t)$ is the desired state of the system, and the heterogeneity function $y$ is a control denoted by $y=u$. The vector function $\hat{u} \in H_{\partial}^{2}(\mathfrak{U})$ minimizing functional (11) is called the optimal control to problem (6), (7).

Define the control space

$$
H^{2}(\mathfrak{U})=\left\{u \in L_{2}(0, \tau ; \mathfrak{U}): \ddot{u} \in L_{2}(0, \tau ; \mathfrak{U})\right\} .
$$

The space $H^{2}(\mathfrak{U})$ is Hilbert, due to the Hilbert property of $\mathfrak{U}$, with the scalar product

$$
[v, w]=\sum_{q=0}^{2} \int_{0}^{\tau}\left\langle v^{(q)}, w^{(q)}\right\rangle_{\mathfrak{U}} d t
$$

In the space $H^{2}(\mathfrak{U})$, consider the closed and convex subset $\mathfrak{U}_{a d}=H_{\partial}^{2}(\mathfrak{U})$, which is the set of admissible controls.

In the paper [11], the following theorem on the uniqueness of optimal control is proved.

Theorem 5. Let the operator $B$ be $(A, p)$-bounded. Then there exists the unique optimal control of solutions to problem (7) for equation (6) for any $w_{0}, w_{1} \in \mathfrak{X}$ and $y \in H^{2}(\mathfrak{Y})$.

\section{Mathematical Model of Internal Waves}

Let the domain $D$ be the parallelepiped $[0, a] \times[0, b] \times[0, c]$. Mathematical model (2)-(4) can be reduced to Cauchy problem (7) for equation (6).

Introduce the spaces $\mathfrak{X}=W_{2}^{l+2}(D), \mathfrak{Y}=W_{2}^{l}(D)$ and define the operators

$$
A=\Delta, \quad B=-F^{2} \frac{\partial^{2}}{\partial z^{2}}
$$

For any $l \in\{0\} \cup \mathbb{N}$, the operators $A, B \in \mathcal{L}(\mathfrak{X}, \mathfrak{Y})$. Denote by

$$
-\lambda_{k, m, n}^{2}=-\left(\frac{\pi k}{a}\right)^{2}-\left(\frac{\pi m}{b}\right)^{2}-\left(\frac{\pi n}{c}\right)^{2}
$$

the eigenvalues of the Laplace operator $\Delta$, which are numbered in non-increasing order with respect to multiplicity. Denote by

$$
\varphi_{k, m, n}=\sin \left(\frac{\pi k x}{a}\right) \sin \left(\frac{\pi m y}{b}\right) \sin \left(\frac{\pi n z}{c}\right)
$$


the orthogonal eigenfunctions that correspond to $\left\{-\lambda_{k, m, n}^{2}\right\}$ in the sense of the scalar product in $L^{2}(\Omega)$.

Since $\left\{\varphi_{k, m, n}\right\} \subset C^{\infty}(D)$, then

$$
\mu A-B=\sum_{k, m, n=1}^{\infty}\left[-\lambda_{k, m, n}^{2} \mu-F^{2} \lambda_{n}^{2}\right]<\varphi_{k, m, n}, \cdot>\varphi_{k, m, n},
$$

where $\langle\cdot, \cdot\rangle$ is the scalar product in the space $L^{2}(D)$. Construct the equation to determine the relative spectrum:

$$
\lambda_{k, m, n}^{2} \mu+F^{2} \lambda_{n}^{2}=0,
$$

and we obtain the relative spectrum in the form

$$
\mu_{k, m, n}=-\frac{F^{2} \lambda_{n}^{2}}{\lambda_{k, m, n}^{2}}
$$

The relative spectrum $\sigma^{A}(B)=\left\{\mu_{k, m, n}\right\}$ is bounded, because $\left|\mu_{k, m, n}\right| \leq F$. Since the operator $A$ is continuously invertible in the given spaces, then the point $\infty$ is a removable singular point of the $A$-resolvent of the operator $B$. As a result, the conditions of Lemma 1 hold. We construct propagators by Theorem 2 . Since the relative spectrum of the operator $B$ is discrete, we obtain

$$
\begin{gathered}
V_{0}^{t} w_{0}=\sum_{k, m, n=1}^{\infty} \cos \left(\frac{F^{2} \lambda_{n}^{2}}{\lambda_{k, m, n}^{2}} t\right)<\varphi_{k, m, n}, w_{0}>\varphi_{k, m, n}, \\
V_{1}^{t} w_{1}=\sum_{k, m, n=1}^{\infty} \frac{F^{2} \lambda_{n}^{2}}{\lambda_{k, m, n}^{2}} \sin \left(\frac{F^{2} \lambda_{n}^{2}}{\lambda_{k, m, n}^{2}} t\right)<\varphi_{k, m, n}, w_{1}>\varphi_{k, m, n} .
\end{gathered}
$$

Solution to problem (2)-(4) has the form

$$
\begin{aligned}
& w(x, t)=\sum_{k, m, n=1}^{\infty} \cos \left(\frac{F^{2} \lambda_{n}^{2}}{\lambda_{k, m, n}^{2}} t\right)<\varphi_{k, m, n}, w_{0}>\varphi_{k, m, n}+ \\
& +\sum_{k, m, n=1}^{\infty} \frac{F^{2} \lambda_{n}^{2}}{\lambda_{k, m, n}^{2}} \sin \left(\frac{F^{2} \lambda_{n}^{2}}{\lambda_{k, m, n}^{2}} t\right)<\varphi_{k, m, n}, w_{1}>\varphi_{k, m, n}+\int_{0}^{t} V_{1}^{t-s} A_{1}^{-1} Q y(s) d s .
\end{aligned}
$$

By virtue of Theorem 4, the solution given by formula (12) is strong. Define the control space

$$
H^{2}(\mathfrak{U})=\left\{u \in L_{2}(0, \tau ; \mathfrak{U}): \ddot{u} \in L_{2}(0, \tau ; \mathfrak{U})\right\},
$$

and consider the closed and convex subset $\mathfrak{U}_{a d}=H_{\partial}^{2}(\mathfrak{U})$, which is the set of admissible controls. The main result of the paper is the proof of the existence of the unique control $\hat{u} \in H_{\partial}^{2}(\mathfrak{U})$ minimizing the functional $J(w, u)$. Fix $w_{0}, w_{1} \in \mathfrak{X}$ and consider (13) as the map $D: u \rightarrow w(u)$. Then the map $D: H^{2}(\mathfrak{U}) \rightarrow H^{2}(\mathfrak{X})$ is continuous. Therefore, the quality functional depends only on $u$, i.e. $J(w, u)=J(u)$.

Rewrite quality functional (11) in the form

$$
J(u)=\|w(t, u)-\tilde{w}\|_{H^{2}(\mathfrak{X})}^{2}+[v, u],
$$


where $v^{(q)}(t)=N_{q} u^{(q)}(t), q=0,1,2$. Hence

$$
J(u)=\pi(u, u)-2 \lambda(u)+\|\tilde{w}-w(t, 0)\|_{H^{2}(\mathfrak{X})}^{2},
$$

where

$$
\pi(u, u)=\|w(t, u)-w(t, 0)\|_{H^{2}(\mathfrak{X})}^{2}+[v, u]
$$

is a bilinear continuous coercive form on $H^{2}(\mathfrak{U})$, and

$$
\lambda(u)=\langle\tilde{w}-w(t, 0), w(t, u)-w(t, 0)\rangle_{H^{2}(\mathfrak{X})}
$$

is a linear continuous form on $H^{2}(\mathfrak{U})$. Therefore, the conditions of Theorem 1.1 proved in [12] are satisfied.

\section{References}

1. Sobolev S. L. On a New Problem of Mathematical Physics. Izv. Akad. Nauk SSSR. Ser. Mat., 1954, vol. 18, issue. 1, pp. 3-50. (in Russian)

2. Fokin M. V. Hamiltonian Systems in the Theory of Small Oscillations of a Rotating Ideal Fluid. I. Mat. Tr., 2001, vol. 4, no. 2, pp. 155-206. (in Russian)

3. Sviridyuk G. A., Fedorov V. E. Linear Sobolev Type Equations and Degenerate Semigroups of Operators. Utrecht; Boston; Köln; Tokyo, VSP, 2003.

4. Zamyshlyaeva A. A. The Phase Space of a High Order Sobolev Type Equation. The Bulletin of Irkutsk State University. Series Mathematics, 2011, vol. 4, issue 4, pp. 45-57. (in Russian)

5. Demidenko G. V., Uspenskii S. V. Partial Differential Equations And Systems Not Solvable With Respect To The Highest-Order Derivative. New York, Basel, Marcel Dekker, 2003.

6. Sviridyuk G. A., Zamyshlyaeva A. A., Zagrebina S. A. Multipoint Initial-Final Problem for One Class of Sobolev Type Models of Higher Order with Additive "White Noise". Bulletin of the South Ural State University. Series: Mathematical Modeling and Programming, 2018, vol. 11, no. 3, pp. 103-117. DOI: 10.14529/mmp180308.

7. Bogomolov A. V., Dragan S. P., Kharitonov V. V., Sviridyuk G. A., Manakova N. A. Acoustic Safety Assessment Method. The Patent for Invention RU No. 2699737, registration date 2019-09-09; the priority to RU2018134860A on 2018-10-02. (in Russian)

8. Sagadeeva M. A., Zagrebina S. A., Manakova N. A. Optimal Control of Solutions of a Multipoint Initial-Final Problem for Non-Autonomous Evolutionary Sobolev Type Equation. Evolution Equations and Control Theory, 2019, vol. 8, no. 3, pp. 473-488. DOI: $10.3934 /$ eect.2019023.

9. Sviridyuk G. A., Efremov A. A. Optimal Control of Sobolev-Type Linear Equations with Relatively $p$-spectorial Operators. Differ. Equ., 1995, vol. 31, no. 11, pp. $1882-1890$. 
10. Sviridyuk G. A., Manakova N. A. An Optimal Control Problem for the Hoff Equation. J. Appl. Industr. Math., 2007, vol. 1, no. 2, pp. 247-253. DOI: $10.1134 /$ S1990478907020147.

11. Tsyplenkova O. N. Optimal Control in Higher-Order Sobolev-Type Mathematical Models with $(A, p)$-Bounded Operators. Bulletin of the South Ural State University. Series: Mathematical Modeling and Programming, 2014, vol. 7, issue 2, pp. 129-135. DOI: 10.14529/mmp140213. (in Russian)

12. Lyons J. L. Optimal Control of Systems Governed by Partial Differential Equations. Berlin, Springer-Verlag, 1971.

Konstantin Yu. Kotlovanov, PhD Student, Department of Mathematical Equations Physics, South Ural State University, Chelyabinsk, Russian Federation, kotlovanovki@susu.ru.

Evgeniy V. Bychkov, PhD (Math), Associate Professor, Department of Mathematical Equations Physics, South Ural State University, Chelyabinsk, Russian Federation, bychkovev@susu.ru.

Alexey V. Bogomolov, DSc (Techn), Professor, Intelligent Systems Laboratory, St. Petersburg Institute for Informatics and Automation of RAS, Saint-Petersburg, Russian Federation, a.v.bogomolov@gmail.com.

Received February 7, 2020.

УДК 517.9

DOI: $10.14529 /$ jcem200105

\title{
ОПТИМАЛЬНОЕ УПРАВЛЕНИЕ В МАТЕМАТИЧЕСКОЙ МОДЕЛИ ВНУТРЕННИХ ВОЛН
}

\author{
К. Ю. Котлованов, Е. В. Бычков, А. В. Богомолов
}

\begin{abstract}
В статье представлены результаты исследования задачи оптимального управления решениями для математической модели внутренних волн, построенной на основе линейной системы уравнений гидродинамики. Данная модель описывает распространения волн в однородной несжимаемой стратифицированной жидкости. Математическая модель включает в себя уравнение Соболева, условие Коши и Дирихле. В качестве рассматриваемой области в математической модели используется параллелепипед. В данной работе показано существование и единственность сильного решения задачи Коши - Дирихле для уравнения Соболева. Получены достаточные условия существования и единственности решения задачи оптимального управления такими решениями в гильбертовых пространствах. Доказательство существования единственного сильного решения основано на теореме для абстрактного неполного неоднородного уравнения соболевского типа второго порядка и теории относительно p-ограниченных операторов. Приведенная в данной работе теорема существования и единственности оптимального управления для исследуемой задачи основана на работах Ж.-Л. Лионса.

Ключевые слова: уравнения соболевского типа; относительно р-ограниченный оператор; сильное решение; оптимальное управление.
\end{abstract}




\section{Литература}

1. Соболев, С. Л. Об одной новой задаче математической физики / С. Л. Соболев // Изв. АН СССР. Сер. матем. - 1954. - Т. 18, № 1. - С. 3-50.

2. Фокин, М. В. Гамильтоновы системы в теории малых колебаний вращающейся идеальной жидкости. І. / М. В. Фокин // Матем. тр. - 2001. - Т. 4, № 2. C. $155-206$.

3. Sviridyuk, G. A. Linear Sobolev Type Equations and Degenerate Semigroups of Operators / G. A. Sviridyuk, V. E. Fedorov. - Utrecht; Boston; Köln; Tokyo: VSP, 2003.

4. Замышляева, А. А. Фазовое пространство уравнения соболевского типа высокого порядка / А. А. Замышляева // Известия Иркутского государственного университета. Серия Математика. - 2011. - Т. 4, вып. 4. - С. 45-57.

5. Демиденко, Г. В. Уравнения и системы, не разрешенные относительно старшей производной / Г. В. Демиденко, С. В. Успенкий. - Новосибирск: Научная книга, 1998.

6. Sviridyuk, G. A. Multipoint Initial-Final Problem for One Class of Sobolev Type Models of Higher Order with Additive «White Noise» / G.A. Sviridyuk, A. A. Zamyshlyaeva, S. A. Zagrebina // Вестник ЮУрГУ. Серия: Математическое моделирование и программирование. - 2018. - Т. 11, № 3. - С. 103-117.

7. Богомолов, А. В. Способ оценивания акустической безопасности: патент на изобретение RU № 2699737 / А. В. Богомолов, С. П. Драган, В. В. Харитонов, Г. А. Свиридюк, Н. А. Манакова. - Дата регистрации 09.09.2019. Заявка № 2018134860 от 02.10 .2018 .

8. Sagadeeva, M. A. Optimal Control of Solutions of a Multipoint Initial-Final Problem for Non-Autonomous Evolutionary Sobolev Type Equation / M. A. Sagadeeva, S. A. Zagrebina, N. A. Manakova // Evolution Equations and Control Theory. 2019. - V. 8, № 3. - P. 473-488.

9. Свиридюк, Г. А. Оптимальное управление линейными уравнениями типа Соболева с относительно p-секториальными операторами / Г. А. Свиридюк, А. А. Ефремов // Дифференц. уравнения. - 1995. - Т. 31, № 11. - С. 1912-1919.

10. Свиридюк, Г. А. Задача оптимального управления для уравнения Хоффа / Г. А. Свиридюк, Н. А. Манакова // Сиб. журн. индустр. матем. - 2005.- Т. 8, № 2. - C. $144-151$.

11. Цыпленкова, О. Н. Оптимальное управление в математических моделях соболевского типа высокого порядка с $(A, p)$-ограниченными операторами / О. Н. Цыпленкова // Вестник ЮУрГУ. Серия: Математическое моделирование и программирование. - 2014. - Т. 7, № 2. - С. 129-135.

12. Лионс, Ж.-Л. Оптимальное управление системами, описываемыми уравнениями с частными производными / Ж.-Л. Лионс. - М.: Мир, 1972. 
Котлованов Константин Юрьевич, аспирант, кафедра уравнений математической физики, Южно-Уральский государственный университет (г. Челябинск, Российская Федерачия), kotlovanovki@susu.ru.

Бъчков Евгений Викторович, кандидат физико-математических наук, кафедра уравнений математической физики, Южно-Уральский государственный универсиmет (г. Челябинск, Российская Федераиия), bychkоvеv@susu.ru.

Богомолов Алексей Валеръевич, доктор технических наук, профессор, Лаборатория автоматизации научных исследований, СПИИРАН (2. Санкт-Петербург, Российская Федерачия), a.v.bogomolov@gmail.com.

Поступила в редакиию 7 февраля 2020 г. 